\title{
RESEARCH
}

Open Access

\section{Role of preoperative ultrasound mapping in the surgical management of deep infiltrating endometriosis: a prospective observational study}

\author{
Samar M. El-Maadawy ${ }^{1,2^{*}}$ (D) Nesreen Alaaeldin ${ }^{2}$ and Charles B. Nagy ${ }^{3}$
}

\begin{abstract}
Background: Endometriosis is a challenging gynecological condition that has a profound influence on the quality of life of affected women. Transvaginal ultrasound is considered the first-line imaging method in preoperative assessment of the extent and severity of endometriosis. Accurate preoperative mapping can aid the surgeon in patient counselling, selection of the most appropriate surgical method that minimizes the operative and postoperative complications. The aim of our study is to evaluate the accuracy of transvaginal sonography (TVS) in precisely assessing the size, location and extent of deep infiltrating endometriosis (DIE) using a new modified endometriosis mapping proforma with histopathological confirmation. Our prospective observational study included 101 women with clinically suspected DIE who underwent TVS followed by laparoscopy from October 2018 to December 2020 with a maximum of 4 weeks interval. Precise mapping of DIE was done during TVS and laparoscopy. Results were correlated with histopathology findings.

Results: DIE was confirmed by histopathology in 88 patients. Sensitivity and specificity for individual DIE locations were rectovaginal septum $67.9 \%$ and $98.6 \%$; vagina $52.2 \%$ and $98.7 \%$; uterosacral ligaments $82.5 \%$ and $96.2 \%$; torus 96.4\% and 97.3\%; parametrium 68.8\% and 96.9\%; rectum 100\% and 98.8\%; bladder 100\% and $100 \%$, ureters $63.4 \%$ and $99.0 \%$; scar endometriosis $100 \%$ and $100 \%$; pouch of Douglas obliteration $97.7 \%$ and $100 \%$. No statistically significant difference was detected between ultrasound and histopathology size. Ultrasound tended to underestimate the lesion size; the underestimation was more pronounced for lesions $>3 \mathrm{~cm}$. "Butterfly" and "tramtrack" signs are two new sonographic signs related to posterior compartment DIE. No post-operative complications were recorded. There were no cases of DIE recurrence. Eleven out of 22 cases of infertility achieved pregnancy during 18 months follow-up.

Conclusion: TVS provides a thorough and accurate evaluation of the extent of endometriosis. An experienced radiologist can use E-PEP to provide an accurate demonstration of the location and extent of DIE which helps the surgeon select the most appropriate surgical approach ensuring radical treatment of the disease and minimizing short- and long-term complications.
\end{abstract}

Keywords: Endometriosis, Ultrasound imaging, Laparoscopic surgery

\footnotetext{
* Correspondence: samarmaadawy@gmail.com

'Department of Radiology, National Cancer Institute, Cairo University, Cairo,

Egypt

${ }^{2}$ Department of Radiology, Medcare Women and Children Hospital, Sheikh

Zayed Road, P.O Box 215565, Dubai, UAE

Full list of author information is available at the end of the article
}

\section{Springer Open}

(-) The Author(s). 2021 Open Access This article is licensed under a Creative Commons Attribution 4.0 International License, which permits use, sharing, adaptation, distribution and reproduction in any medium or format, as long as you give appropriate credit to the original author(s) and the source, provide a link to the Creative Commons licence, and indicate if changes were made. The images or other third party material in this article are included in the article's Creative Commons licence, unless indicated otherwise in a credit line to the material. If material is not included in the article's Creative Commons licence and your intended use is not permitted by statutory regulation or exceeds the permitted use, you will need to obtain permission directly from the copyright holder. To view a copy of this licence, visit http://creativecommons.org/licenses/by/4.0/. 


\section{Background}

Endometriosis is a challenging gynecological condition that has a profound influence on the quality of life of affected women. It is described as ectopic endometrial tissue present outside the uterus affecting women of the reproductive age group with a prevalence of about $10 \%$ [1]. Deep infiltrating endometriosis (DIE) is defined as the presence of endometriotic tissue, smooth muscle hyperplasia and fibrosis below the peritoneum $5 \mathrm{~mm}$ in depth accounting for about 15 to $30 \%$ of all endometriosis cases [2, 3].

The most prevalent manifestations include infertility, dysmenorrhea, dyspareunia, pelvic pain, dyschezia and urinary symptoms [4]. DIE-induced symptoms are non-specific, often leading to missed or delayed diagnosis $[5,6]$.

Physical examination is known to have limitations in the diagnosis and quantification of DIE [7, 8]. Having a reliable imaging modality to specify the extent and location of DIE preoperatively plays a key role in surgical planning [9]. The exact surgical approach and participating multispecialty surgical team are largely dependent on preoperative diagnostic evaluation.

Diagnostic laparoscopy is widely recognized as the gold standard for the diagnosis of endometriosis. However, it has its own limitations when it comes to the assessment of pelvic, deep infiltrating or extra-pelvic endometriosis [10]. Transvaginal sonography (TVS) and magnetic resonance imaging (MRI) have been well documented to diagnose and specify DIE locations and are widely used imaging techniques in clinical practice [1113]. In addition to being cost effective, TVS has been shown to be comparable to MRI in the diagnosis of endometriosis and is considered the first-line imaging method [14-16].

Previous studies have attempted to map DIE preoperatively $[9,17]$. The purpose of our study is to evaluate the accuracy of TVS in diagnosing DIE by comparing imaging findings with laparoscopy and histopathology using a new modified endometriosis mapping proforma that can be interpreted easily by the radiologists and surgeons in which the precise location, size and extent of lesions are defined to assist in surgical planning minimizing operative and post-operative complications.

\section{Methods}

This prospective observational single-institution study included all consecutive patients with clinically suspected endometriosis who underwent ultrasound followed by laparoscopy from October 2018 to December 2020. The study was approved by the Institutional Ethics Committee. Written informed consent was obtained from all patients who agreed to take part in this study. The study was reported in accordance with the Standards for Reporting for Diagnostic accuracy studies (STARD guidelines) [18].
Inclusion criteria included premenopausal women with suspected DIE who are willing to undergo TVS or, in the case of virgin females, transrectal sonography (TRS) followed by laparoscopy. Exclusion criteria included patients who refused TVS or TRS, patients who performed ultrasound at an outside facility or did only MRI, patients who were not eligible or refused surgery and patients who lacked informed consent.

DIE was clinically suspected based on detailed clinical history and physical examination. A case history proforma was obtained for all cases by the surgeon which included symptoms, parity, previous medical and surgical treatments and infertility with pregnancy outcome when applicable. A visual analogue scale (VAS) was recorded for all patients from $0-10$ where 0 corresponds to no pain and 10 is the maximum pain $[19,20]$.

\section{Endometriosis mapping proforma}

We developed an Endometriosis Preoperative Evaluation Proforma (E-PEP) which is a new modified preoperative mapping tool used to assess the severity and extent of endometriosis in a standardized staged manner used during our TVS protocol for cases with suspected DIE in four basic steps: uterus, adnexal endometriosis, Douglas pouch obliteration and finally DIE mapping. The E-PEP is filled by marking the site and size of endometriosis with schematic diagrams to sketch the DIE locations. The E-PEP was marked by the radiologist after TVS then by the surgeon after laparoscopy who was blinded to the radiologists' mapping findings. (Fig. 1).

\section{Ultrasound examination}

All ultrasound examinations were conducted transvaginally except for four virgin females in which TRS was performed using a Voluson E8 (GE Healthcare) ultrasound machine with a 5-9-MHz transvaginal transducer. The examination was done at any time irrespective of the menstrual phase with a partially filled urinary bladder. No bowel preparation was needed. Conventional 2D and 3D volume acquisition using tomographic ultrasound imaging (TUI) and volume contrast imaging (VCI) was used. The ultrasound studies were performed by two radiologists who are highly experienced in the field of women imaging particularly TVS assessment of DIE. Between ultrasound and surgery, patients had a maximum interval of 4 weeks.

Our ultrasound protocol follows the consensus statement from the International Deep Endometriosis Analysis (IDEA) group [21]. The uterine position is assessed whether anteverted, retroverted or with isolated retraction of the uterine fundus which gives an indication about the presence of adhesions and POD obliteration [22]. The uterus is then examined for signs of adenomyosis which is commonly associated with endometriosis [23]. Next, ovaries are evaluated for cysts particularly endometriomas with the 

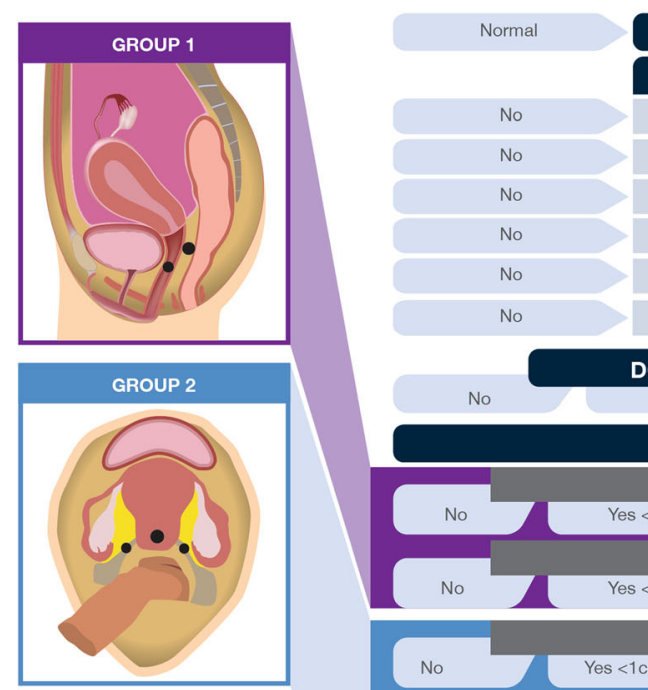

\section{\begin{tabular}{|c|} 
UTERUS \\
ADNEXAL ENDOMETRIOSIS
\end{tabular}}

ENDOMETRIOMA (right ovary)

ADHESIONS (right ovary)

RIGHT HYDROSALPINX

ENDOMETRIOMA (left ovary)

ADHESIONS (left ovary)

LEFT HYDROSALPINX

Adenomyosis

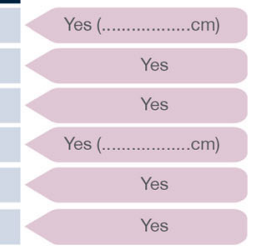

DOUGLAS POUCH OBLITERATION
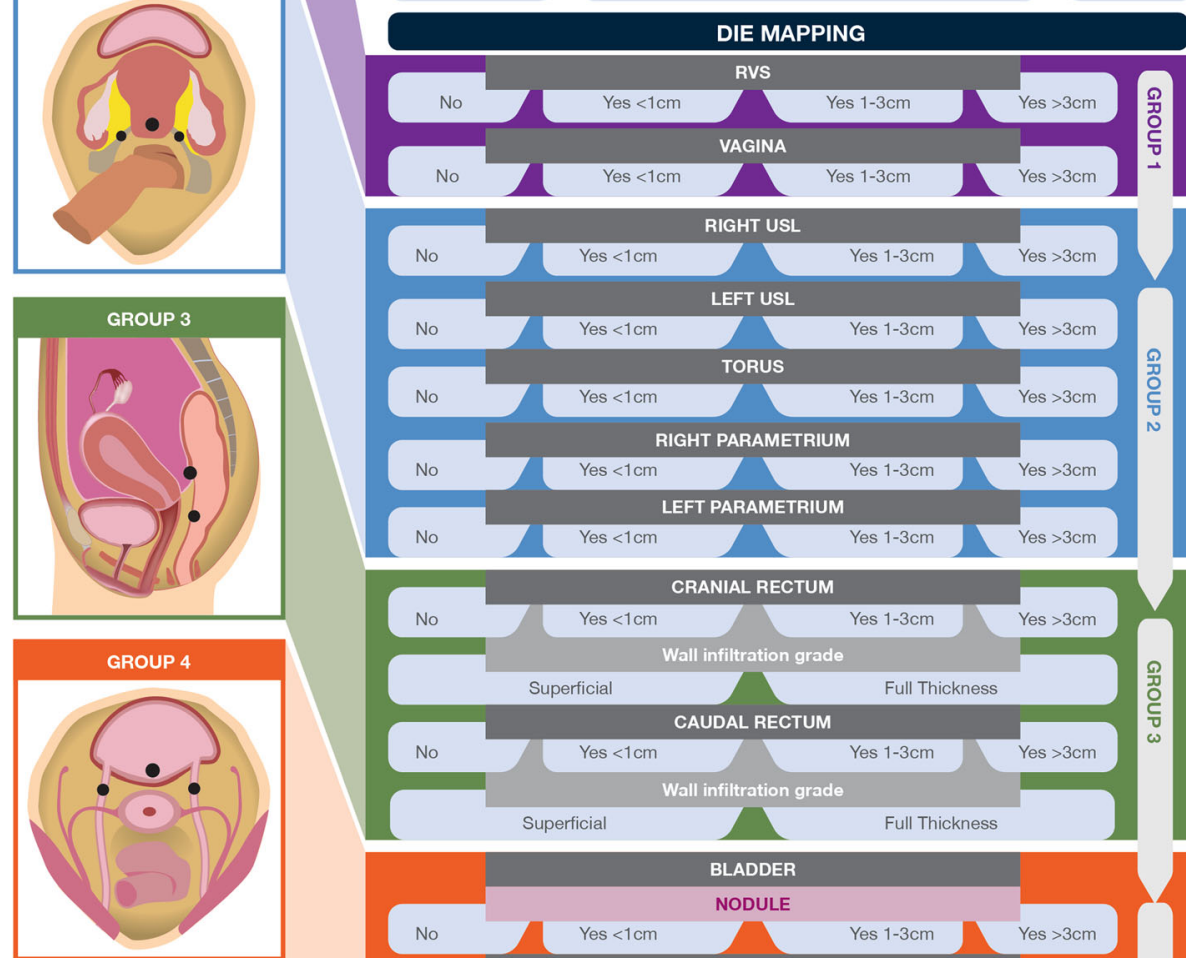

No

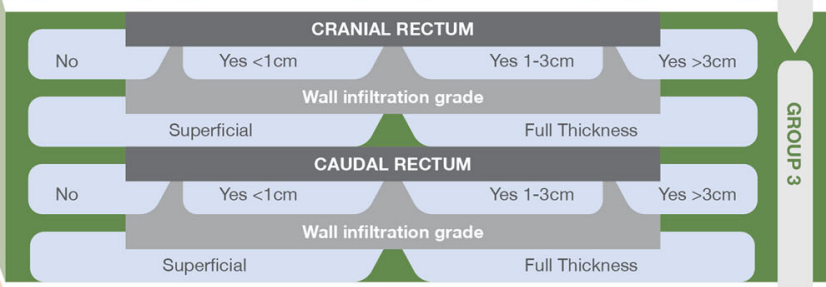

GROUP 5
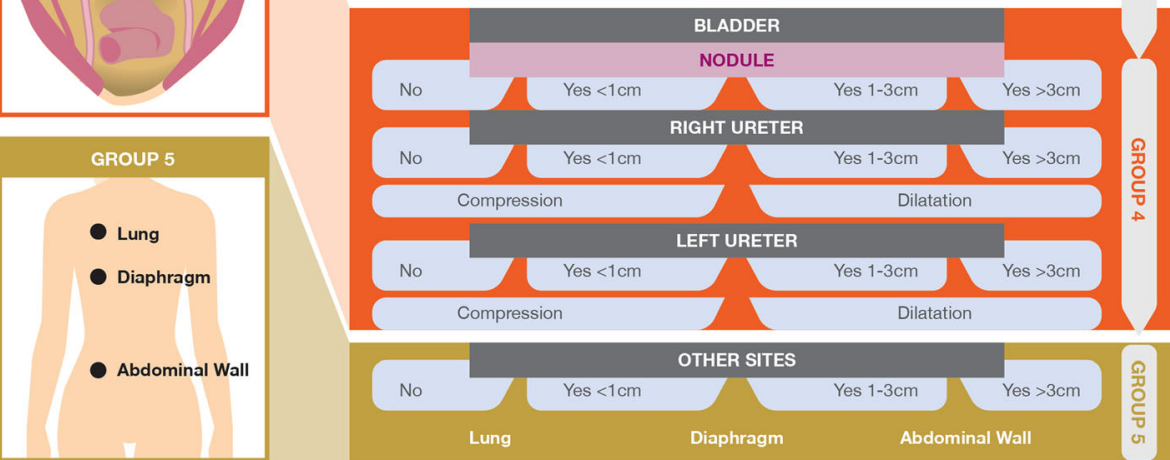

Fig. 1 Endometriosis Preoperative Evaluation Proforma (E-PEP). The proforma is filled out and marked according to ultrasound and laparoscopy findings. The site of deep infiltrating endometriosis can be also sketched in the schematic diagrams on the left corresponding to each group

typical low-grade echoes of "ground glass" appearance [24]. The adnexa are then evaluated for signs of hydrosalpinx and peritoneal inclusion cysts. Evaluation of ovarian mobility is done by vaginal probe pressure and/or abdominal pressure using the free hand of the examiner. Free mobility of the ovaries in relation to surrounding structures indicates the absence of adhesions [25]. The "sliding sign" is utilized to reveal partial or complete Pouch of Douglas obliteration [22].

The final step is mapping of DIE. Tenderness-guided sonography is a key approach in pathological site detection when searching for DIE [26]. We divided DIE into the following five groups inspired from the Enzian classification [27]: 


\section{Group 1:}

- Rectovaginal septum (RVS)

- Vagina

\section{Group 2:}

- Right uterosacral ligament (USL)

- Left USL

- Torus uterinum

- Right parametrium

- Left parametrium

\section{Group 3:}

- Cranial rectum

- Caudal rectum

\section{Group 4:}

- Bladder

- Right ureter

- Left ureter

\section{Group 5:}

- Other locations including scar endometriosis

DIE nodules have different characteristics depending on the anatomical location and diagnosis when irregular hypoechoic nodular lesions adherent to the surrounding structures are identified with tenderness on probe pressure [28]. Caudal rectal lesions were defined as plaques found below the level of USL, while those above this level considered rectosigmoid junction or cranial rectal lesions [9]. Involvement of the rectal wall appears as irregular hypoechoic thickening of the bowel wall that may lead to luminal compromise [29]. The largest diameter of the lesions was recorded.

\section{Surgery}

A laparoscopic approach was adopted for all 101 cases. All cases were performed by the same surgeon who had specific training in managing difficult deep endometriosis cases by laparoscopy; some cases were carried out in collaboration with a colorectal surgeon and urologist.

Initial assessment of the extent of the disease was carried out guided by the ultrasound report findings plus visual and tactile assessment for superficial and deep endometriotic nodules. For lesions involving the uterosacral ligaments, uterine torus, rectosigmoid colon or parametrium, ureterolysis was carried out first and then opening of the medial para-rectal space and sparing of the hypogastric nerves then proceeding to dissection of the rectovaginal space before excision of the endometriotic nodules. Rectosigmoid nodules were excised mostly using the shaving technique with only few cases needing rectal disc excision or segmental bowel resection in cases of sub-occlusive lesions. Bowel lesions greater than $3 \mathrm{~cm}$ in length and more than $0.5 \mathrm{~cm}$ in depth were not suitable for adequate shaving and needed disc excision. Lesions causing luminal compromise or involving $50 \%$ or more of the bowel circumference needed segmental bowel resection. Ovarian endometriomas were excised using the stripping technique. Lesions involving the vagina were removed using full-thickness excision of the vaginal wall. Surgical findings were documented using the British Society for Gynecological Endoscopy (BSGE) surgical data sheet [30].

Following surgery, all specimens were sent to the same laboratory for histopathological confirmation.

\section{Statistical analysis}

Data were statistically described in terms of mean \pm standard deviation $( \pm \mathrm{SD})$. Numerical data were tested for the normal assumption using the KolmogorovSmirnov test. A comparison between TP lesions and missed lesions was done using the Mann-Whitney $U$ test for independent samples. Comparison between US size and pathological size within TP lesions was done using a paired $t$ test. Agreement between the size measured by US and pathology was done using interclass correlation (ICC) coefficient. $p$ values less than 0.05 were considered statistically significant. All statistical calculations were done using the computer program IBM SPSS (Statistical Package for the Social Science; IBM Corp, Armonk, NY, USA) release 22 for Microsoft Windows.

\section{Results}

Patient flow, demographics and clinical characteristics

One hundred and thirty-five women were initially enrolled. Twenty-nine patients who refused TVS or TRS, performed ultrasound at an outside facility or did only MRI were initially excluded. One hundred and six patients eventually performed standardized TVS/TRS and were eligible for surgery. Fifteen patients who had no evidence of DIE on ultrasound were still qualified for surgery due to the presence of endometriomas in $10 \mathrm{pa}-$ tients and adenomyosis with severe pelvic pain in five patients. Five patients refused surgery. Following exclusion criteria, 101 patients were ultimately included in our study (Fig. 2).

Study population characteristics are summarized in Table 1.

\section{Accuracy of TVS in individual DIE locations}

Eighty-eight women were found to have DIE as confirmed on laparoscopy and histopathology. Ultrasound detected DIE in 86 cases (85.1\%) and laparoscopy 


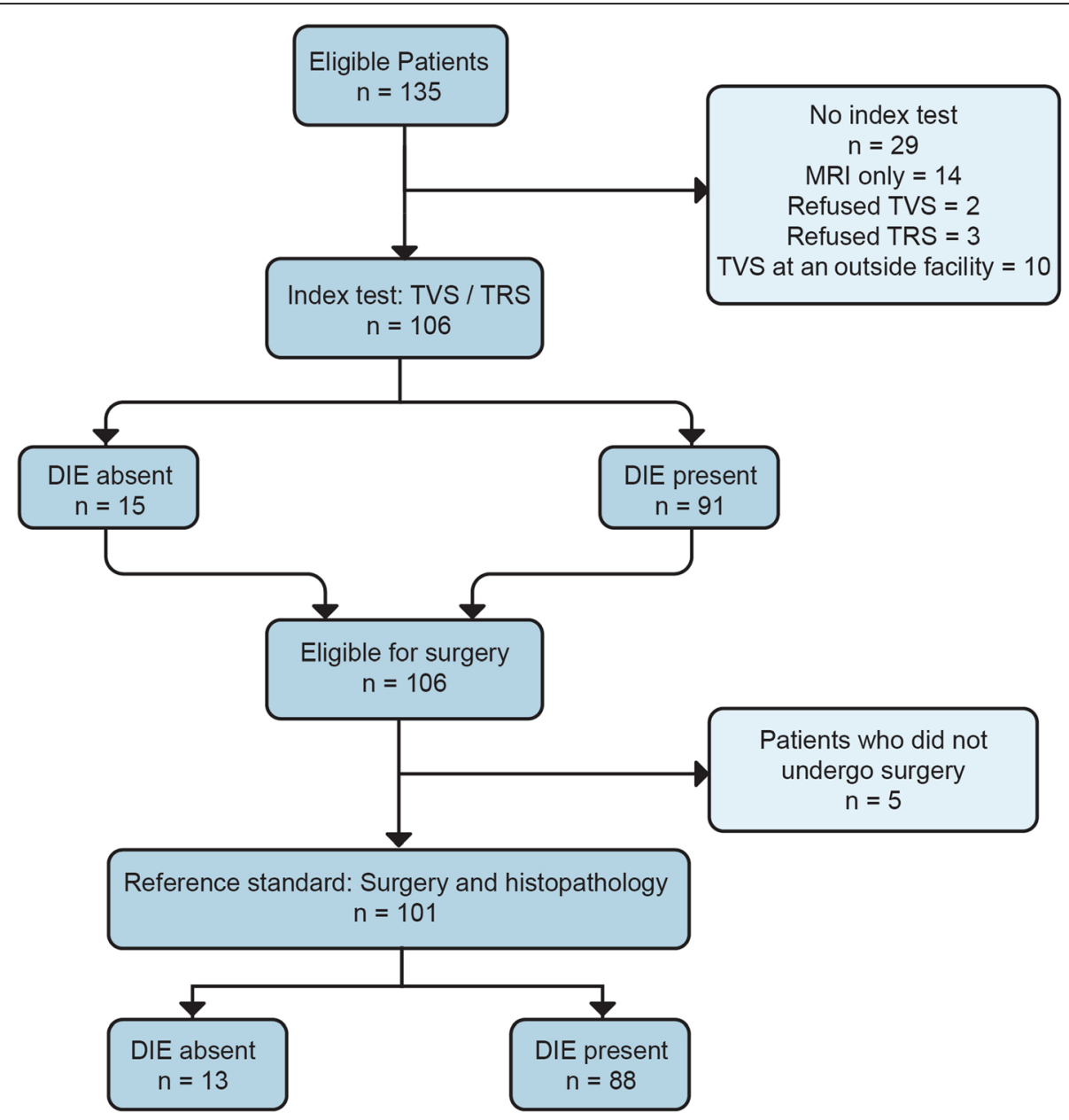

Fig. 2 Flow diagram of the study population based on STARD recommendation

detected DIE in two additional cases; each had a solitary plaque of DIE at the left USL.

The performance of TVS for each individual DIE location is shown in Table 2. Vaginal DIE was found to have the lowest sensitivity and accuracy with a sensitivity of $52.2 \%$ and accuracy of $88.1 \%$, while bladder DIE and scar endometriosis were shown to have the highest sensitivity and accuracy with a value of $100 \%$ (Fig. 3).

Adenomyosis was observed by ultrasound in 36 cases (35.6\%) all of which were associated with DIE, except for six cases (16.7\%). Ovarian endometriomas were seen in 79 cases $(78.2 \%)$. The right ovary was involved in 59 cases $(58.4 \%)$, the left ovary in 47 cases $(46.5 \%)$ and bilateral endometriomas in 27 cases (26.7\%). DIE was associated with ovarian endometriomas in 72 out of 79 cases (91.1\%) and without ovarian endometriomas in 13 out of 22 cases (59.1\%).

Pouch of Douglas obliteration was seen by ultrasound in 84 cases $(83.2 \%)$. Complete obliteration was seen in 34 cases (33.7\%) with 33 out of 34 cases (97.1\%) showing evidence of DIE by TVS. The sensitivity and accuracy of TVS in detecting pouch of Douglas obliteration was high at $97.7 \%$ and $98.0 \%$ respectively.

USL involvement by DIE was seen by ultrasound in 60 cases (59.4\%). Bilateral USL involvement was seen in 23 cases (22.8\%). TVS was accurate in detecting USL DIE with an accuracy of $92.1 \%$ and $88.1 \%$ on the right and left sides, respectively. The torus was almost always affected with bilateral USL involvement with 22 out of 23 cases (95.7\%) of bilateral USL DIE showing torus plaques resulting in a "butterfly" configuration. In the sagittal view, we observed that USL and rectal bowel loop involvement gave a "tram-track" configuration caused by thickening of the affected USL and bowel loop with intervening increased tissue echogenicity caused by associated perilesional fibrotic and chronic inflammatory changes (Fig. 4).

Ultrasound revealed DIE of the rectum in 42 cases (41.6\%). The cranial rectum was affected in 24 cases (23.8\%) and the caudal rectum in 18 cases (17.8\%). The 
Table 1 Study population characteristics

\begin{tabular}{|c|c|}
\hline $\begin{array}{l}\text { Patient characteristics signs and } \\
\text { symptoms (No. 101) }\end{array}$ & $\begin{array}{l}\text { Mean +/- SD; } \\
\text { No. }(\%)\end{array}$ \\
\hline Age(y) & $37.1 \pm 6.2$ \\
\hline \multicolumn{2}{|l|}{ Parity } \\
\hline 0 & $63(62.4)$ \\
\hline $1-2$ & $28(27.7)$ \\
\hline$\geq 3$ & $10(9.0)$ \\
\hline Previous medical treatment & $82(81.2)$ \\
\hline Duration of medical treatment (mo) & $5.9 \pm 6.8$ \\
\hline Previous surgery of endometriosis & $30(29.7)$ \\
\hline \multicolumn{2}{|l|}{ Number of previous surgical intervention } \\
\hline 0 & $70(69.3)$ \\
\hline $1-2$ & $25(24.8)$ \\
\hline$\geq 3$ & $6(5.9)$ \\
\hline Dysmenorrhea & $101(100)$ \\
\hline VAS score ${ }^{a}$ & $8.8 \pm 1.4$ \\
\hline Pelvic pain & $97(96.0)$ \\
\hline VAS score ${ }^{a}$ & $7.5 \pm 1.5$ \\
\hline Deep dyspareunia & $68(67.3)$ \\
\hline VAS score ${ }^{a}$ & $6.6 \pm 1.3$ \\
\hline Dyschezia & 39 (38.6) \\
\hline VAS score ${ }^{a}$ & $6.8 \pm 1.68$ \\
\hline Dysuria/frequency & $12(11.9)$ \\
\hline Infertility ${ }^{b}$ & $22(21.8)$ \\
\hline \multicolumn{2}{|l|}{ Infertility duration (y) } \\
\hline 2 & $4(4.0)$ \\
\hline 3 & $8(7.9)$ \\
\hline$\geq 4$ & $10(9.9)$ \\
\hline Incomplete rectal emptying & 19 (18.8) \\
\hline Constipation & $69(68.3)$ \\
\hline Diarrhoea & $9(8.9)$ \\
\hline
\end{tabular}

No number, SD standard deviation, mo month, $y$ year

a Visual analogue scale (VAS) (ranges from 0 to 10 , with 0 corresponding to no pain and 10 corresponding to maximum pain). ${ }^{b}$ Infertility is defined as failure of sexually active non-contraceptive couple to conceive after 1 year

accuracy and sensitivity of TVS was very high for the cranial and caudal rectum at $100 \%$ and $99 \%$ respectively with no missed lesions and only one false positive lesion at each site. Thirty-six cases were treated with rectal shaving and five cases with disc excision. One case performed segmental bowel resection due to involvement of the bowel wall more than $60 \%$ of the circumference associated with luminal compromise; therefore, shaving or disc excision was not appropriate. Histopathological assessment of cases with disc excision and segmental bowel resection revealed mucosal involvement. In cases where shaving was done, histopathology confirmed muscular layer involvement. Ultrasound showed a 100\% accuracy in detecting muscular layer involvement and $50 \%$ for mucosal involvement (Fig. 5).

Ureteric involvement was seen in six patients (5.9\%), three of which (3\%) were bilateral. TVS detected a total of eight extrinsic and one intrinsic ureteric lesion with a sensitivity of $63.4 \%$ and accuracy of $97 \%$. Ureteric reimplantation was performed for the intrinsic and stenting for the extrinsic lesions.

\section{Correlation between ultrasound and histopathology size}

A comparison of US size and pathology size of true positive (TP) lesions for each group is shown in Table 3. There was no statistically significant difference between the ultrasound size and pathology size except in groups 4 and 5 which is mostly due to the small number of lesions in these groups. Except for group 3, ultrasound appeared to underestimate lesions size with a mean difference ranging from $0.43 \mathrm{~cm}$ in group 2 to $0.75 \mathrm{~cm}$ in group 5 . For larger lesions $>3 \mathrm{~cm}$, the underestimation was more pronounced, with a mean difference ranging from $0.86 \mathrm{~cm}$ in group 2 to $1.7 \mathrm{~cm}$ in group 1.

\section{Correlation between TP lesions and missed lesions}

We compared the size of TP lesions and missed lesions in groups 1, 2 and 4. No missed lesions were recorded in groups 3 and 5 . There was no statistically significant difference between the size of TP cases and missed lesions with $p$ values of $0.168,0.812$ and 0.637 , respectively. The mean diameter of missed lesions was $1.2 \mathrm{~cm}$ for groups 1 and 4 and $1.6 \mathrm{~cm}$ for group 2 .

\section{Operative complications and fertility outcome}

No operative or post-operative complications were recorded in our study population which reflects the multidisciplinary approach. Over a period of up to 2 years of follow-up, we had no cases of recurrent DIE. Eleven out of 22 cases $(50 \%)$ of infertility achieved pregnancy over a period of 18 months, all of which were spontaneous except for two cases requiring in vitro fertilization (IVF).

\section{Discussion}

In our study, we showed that TVS allows for thorough and accurate evaluation of the extent of endometriosis. Experienced radiologists can use E-PEP to provide accurate demonstration of the location and extent of DIE which aids the surgeon in preoperative assessment and intra-operative management.

As reported by Exacoustos et al., our study showed high sensitivity and accuracy of TVS in detecting pouch of Douglas obliteration [9]. This was contrasted with Fratelli et al. which could be explained by their retrospective study design [31]. We also found strong correlation with complete pouch of Douglas obliteration and presence of DIE with $97.1 \%$ with complete obliteration 
Table 2 Accuracy of TVS in diagnosing DIE with laparoscopy and histopathology as the gold standard

\begin{tabular}{|c|c|c|c|c|c|c|c|c|}
\hline DIE Localization & Prevalence \% (n) & Sensitivity (\%) & Specificity (\%) & PVP (\%) & PVN (\%) & LR+ & LR- & Accuracy (\%) \\
\hline \multicolumn{9}{|l|}{ Group 1} \\
\hline Rectovaginal septum & $19.8(20)$ & 67.9 & 98.6 & 95.0 & 88.9 & 48.5 & 0.33 & 90.1 \\
\hline Vagina & $12.9(13)$ & 52.2 & 98.7 & 92.3 & 87.5 & 40.2 & 0.48 & 88.1 \\
\hline \multicolumn{9}{|l|}{ Group 2} \\
\hline Right USL & $42.6(43)$ & 84.0 & 98.0 & 97.7 & 86.2 & 42.0 & 0.16 & 91.1 \\
\hline Left USL & $40.6(41)$ & 80.9 & 94.4 & 92.7 & 85.0 & 14.5 & 0.20 & 88.1 \\
\hline Torus uterinum & $28.7(29)$ & 96.4 & 97.3 & 93.1 & 98.6 & 35.2 & 0.04 & 97.0 \\
\hline Right parametrium & $19.8(20)$ & 73.9 & 96.2 & 85.0 & 92.6 & 19.5 & 0.27 & 91.1 \\
\hline Left parametrium & $15.8(16)$ & 63.6 & 97.5 & 87.5 & 90.6 & 25.4 & 0.37 & 90.1 \\
\hline \multicolumn{9}{|l|}{ Group 3} \\
\hline Cranial rectum & $23.8(24)$ & 100.0 & 98.7 & 95.8 & 100.0 & 76.9 & 0.00 & 99.0 \\
\hline Caudal rectum & $17.8(18)$ & 100.0 & 98.8 & 94.4 & 100.0 & 83.3 & 0.00 & 99.0 \\
\hline \multicolumn{9}{|l|}{ Group 4} \\
\hline Bladder & $3.0(3)$ & 100.0 & 100.0 & 100.0 & 100.0 & - & 0.0 & 100.0 \\
\hline Right ureter & $5.0(5)$ & 66.7 & 98.9 & 80.0 & 97.9 & 60.6 & 0.34 & 97.0 \\
\hline Left ureter & $4(4)$ & 60.0 & 99.0 & 75.0 & 97.9 & 60.0 & 0.40 & 97.0 \\
\hline \multicolumn{9}{|l|}{ Group 5} \\
\hline $\begin{array}{l}\text { Scar/anterior abdominal } \\
\text { wall endometriosis }\end{array}$ & $4(4)$ & 100.0 & 100.0 & 100.0 & 100.0 & - & 0.00 & 100.0 \\
\hline
\end{tabular}

DIE deep infiltrating endometriosis, $P V P$ positive predictive value, $P V N$ negative predictive value, $L R+$ positive likelihood ratio, $L R-$ negative likelihood ratio, $U S L$ uterosacral ligament
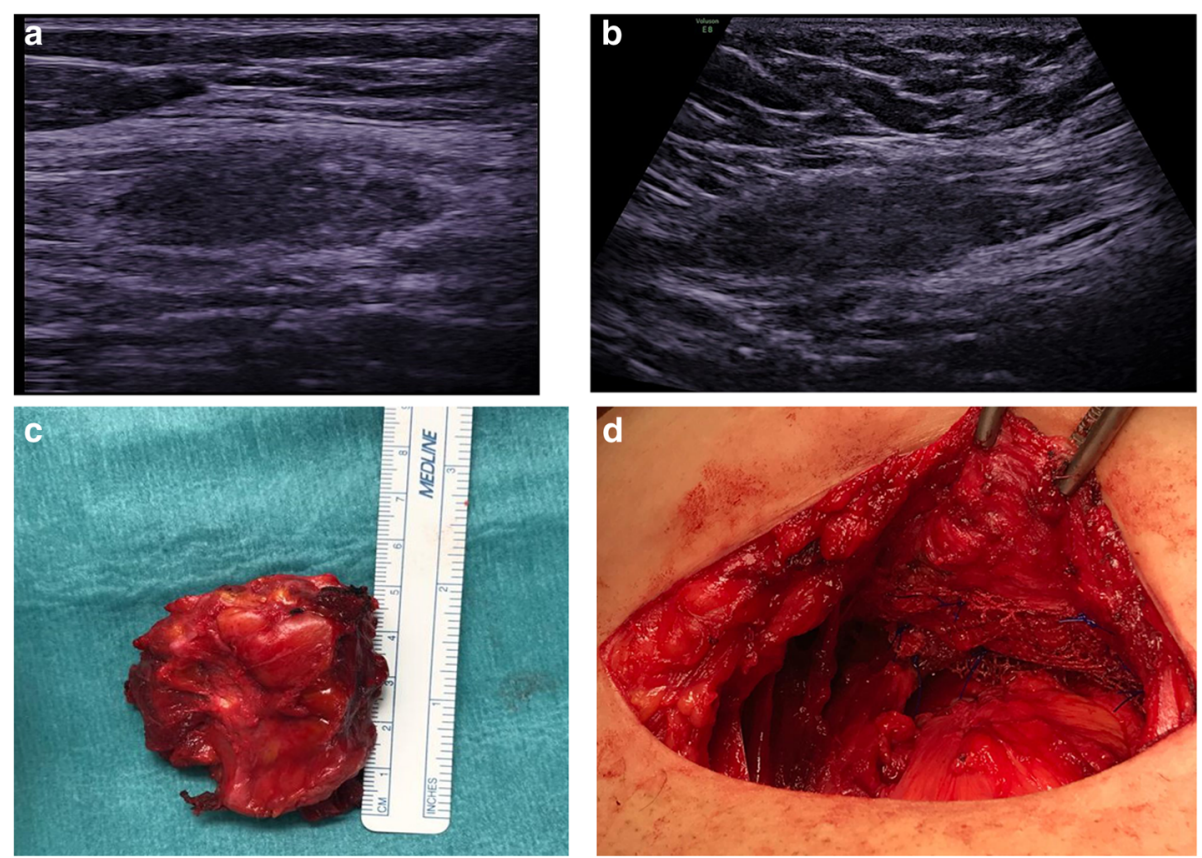

Fig. 3 a Axial and $\mathbf{b}$ sagittal ultrasound images in a 36-year-old woman with pathologically proven scar endometriosis related to previous a caesarean section scar. An irregularly shaped hypoechoic lesion inseparable from the anterior abdominal wall muscle was noted. $\mathbf{c}$ and $\mathbf{d}$ Intraoperative photographs showing the dissected lesion. Part of the abdominal wall muscle had to be dissected with the insertion of a mesh 

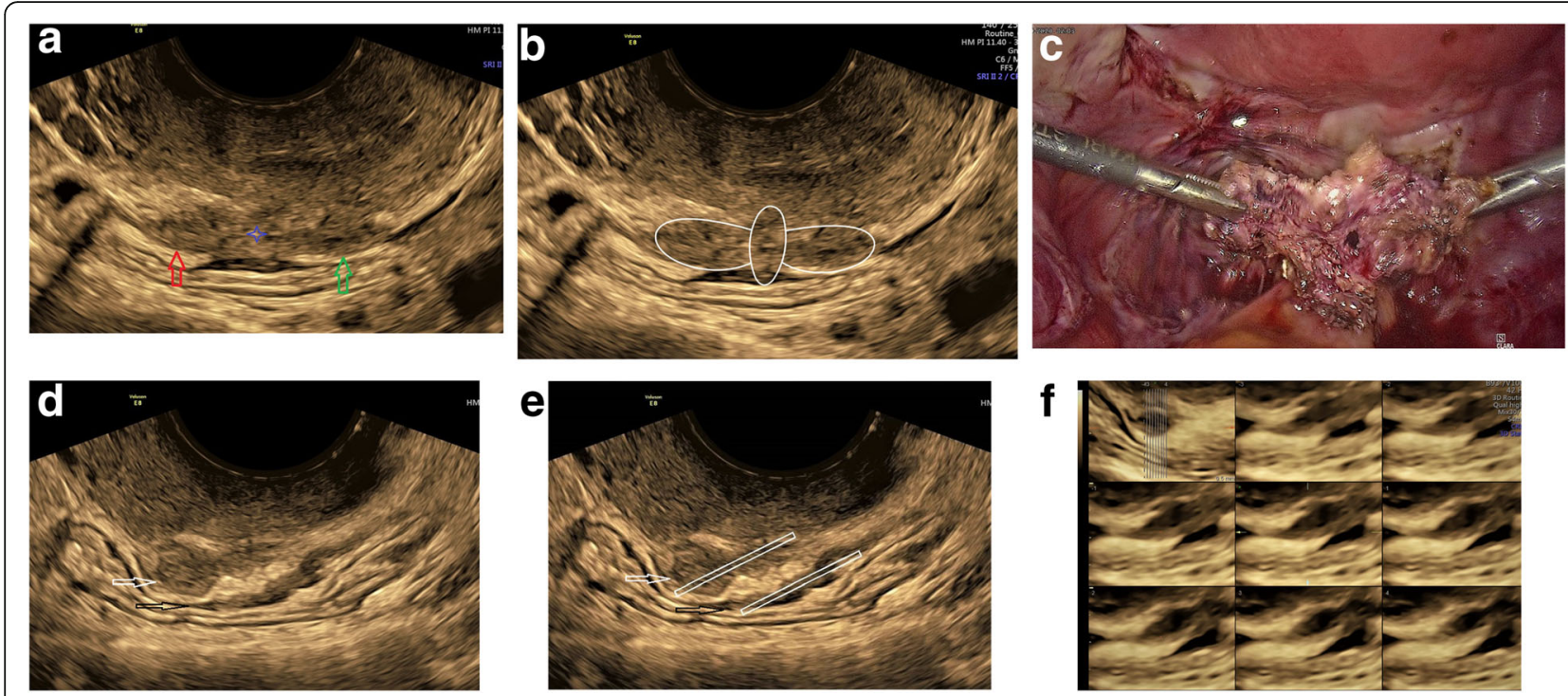

Fig. 4 a and $\mathbf{b}$ Transverse TVS image at the level of USL in a 35-year-old woman showing right and left USL (red and green arrows) as well as torus uterinum DIE (blue star) giving a "butterfly" configuration. c Intraoperative photograph showing the butterfly lesion. $\mathbf{d}$ and e Sagittal TVS image showing left USL (white arrow) and caudal rectal bowel DIE (black arrow) giving a "tram-track" configuration. $\mathbf{f}$ 3D volume acquisition of the "tram-track" lesion using tomographic ultrasound imaging (TUI)

showing signs of DIE by TVS as observed by Reid et al. [22]. Therefore, complete pouch of Douglas obliteration should warrant meticulous search for DIE.

The lowest sensitivity and accuracy in our study was reported in vaginal DIE with a sensitivity of $52.2 \%$ and accuracy of $88.1 \%$, similarly observed in previous studies $[9,28]$. This may be due to vaginal probe characteristics we used which provides suboptimal structure detection near the tip of the probe. Two studies reported higher sensitivity values of $67 \%$ and $62 \%$ respectively $[32,33]$.
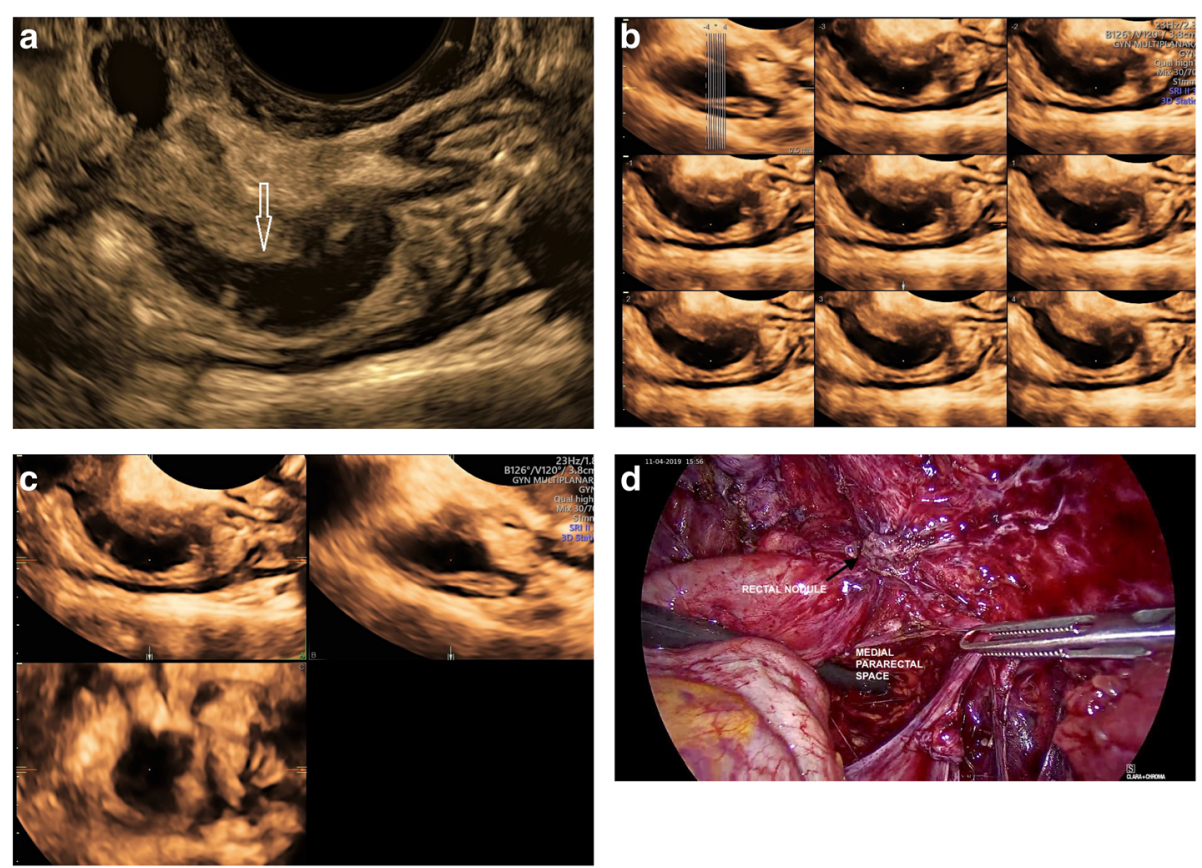

Fig. 5 a Sagittal TVS image in a 37-year-old woman showing a full-thickness plaque of DIE at the caudal rectum with subsequent luminal compromise. $\mathbf{b}$ 3D volume acquisition of the rectal DIE using tomographic ultrasound imaging (TUI) in a sagittal plane and $\mathbf{c}$ volume contrast imaging $(\mathrm{VCl})$ in sagittal, axial and coronal planes. $\mathbf{d}$ Intraoperative photograph showing the rectal plaque (black arrow) before shaving 
Table 3 Correlation between ultrasound size and histopathology size

\begin{tabular}{lllll}
\hline Group & $\begin{array}{l}\text { US size }(\mathbf{c m}) \\
\text { Mean } \pm \text { SD }\end{array}$ & $\begin{array}{l}\text { Pathology size }(\mathbf{c m}) \\
\text { Mean } \pm \text { SD }\end{array}$ & ICC & $P$ \\
\hline 1 & $1.35 \pm 0.32$ & $1.89 \pm 0.75$ & 0.68 & 0.002 \\
2 & $1.63 \pm 0.41$ & $2.05 \pm 0.50$ & 0.69 & 0.000 \\
3 & $2.69 \pm 1.0$ & $2.65 \pm 0.91$ & 0.92 & 0.000 \\
4 & $1.27 \pm 0.51$ & $1.65 \pm 0.35$ & 0.84 & 0.365 \\
5 & $2.63 \pm 0.92$ & $3.38 \pm 1.11$ & 0.97 & 0.030 \\
\hline ICC interclass correlation & & &
\end{tabular}

However, they included a fewer number of patients with 48 and 65 patients meeting their inclusion requirements. A study by Guerriero and colleagues which included 88 patients reported a high sensitivity of $91 \%$ [34]. Their results could be explained by using a generous amount of gel inside the transvaginal probe cover establishing a "stand-off". Koninckx et al. proposed using a clinical approach in diagnosing vaginal DIE rather than imaging with TVS which they considered to be operator dependant [4]. We believe that clinical examination should complement ultrasonography when assessing vaginal DIE.

The most frequently encountered location of DIE in our series was USL with $59.4 \%$ prevalence similarly stated by previous studies $[28,31]$. Our sensitivity and specificity were high at $82.5 \%$ and $98.4 \%$ respectively similar to previously published results $[9,16,33,35]$. Other investigators reported lower sensitivity and specificity [28, 31, 32, 36, 37]. In our series, the torus was almost always affected with bilateral USL involvement with $95.7 \%$ of bilateral uterosacral DIE showing torus plaques. In our experience, torus involvement should be carefully looked for with bilateral USL disease. We described two new sonographic signs: the "butterfly" and "tram-track" signs. To the best of our knowledge, these two signs were not described in the literature before. The reproducibility of these two new signs needs further evaluation.

We found very high sensitivity and accuracy of TVS in cranial and caudal rectal DIE at 100\% and 99\% respectively. Several authors reported high sensitivities of more than $90 \%[9,28,33,38]$. Other investigators reported lower sensitivities of less than $50 \%[35,36]$. However, both studies had a low incidence of bowel involvement in their sample population. Our study showed low accuracy in detecting the involvement of the mucosal layer as published by previous investigators $[9,28,39]$. However, we cannot draw firm conclusions from our figures since only six patients who performed segmental bowel resection and disc excisions could be analysed. We believe that the decision for surgery should be based on clinical history, pelvic examination and imaging findings.
We adopted a conservative surgical approach for rectosigmoid DIE favouring bowel shaving and disc excision over segmental bowel resection. A conservative surgical technique has been shown to compare favourably to segmental bowel resection with regard to surgical, functional outcomes and recurrence rate [40, 41].

In our study, $100 \%$ sensitivity and accuracy were observed in DIE of the bladder close to published results by other investigators $[9,16,28,33,35,36]$. However, we only had three lesions in our series therefore, no sufficient data is available to draw firm conclusions. TVS detected a total of eight extrinsic and one intrinsic ureteric lesions with a sensitivity of $63.4 \%$ and accuracy of 97\% similar to the results published by Exacoustos et al. who concluded that the incidence of intrinsic ureteric DIE is low as well as its associated hydroureter with low sensitivity of TVS [9]. We also agree with their interpretation that extrinsic involvement should be suspected with DIE involving the USL and parametrium.

There was no statistically significant difference between the size DIE nodules detected by TVS and size reported by histopathology which was consistent with a previous study [32]. The only statistical difference was observed in groups 4 and 5 which could be due to the small number of lesions in these groups. The ultrasound tended to underestimate the lesion size which was more pronounced in lesions $>3 \mathrm{~cm}$ in line with Leone et al.'s study [42]. We suggest that the underestimation in larger lesions may be attributable to extensive surrounding fibrosis as well as the location that is difficult to be evaluated by TVS. This was especially obvious in lesions located in group 1.

We found no statistically significant difference between the size of TP lesions and missed lesions in contrast to results published by Fratelli et al. [31]. Therefore, we can conclude that the site rather than the size of the lesion is more significant in lesion detection.

The limitation of our study is the high occurrence of endometriosis because of the way the patients were selected and the setting of the study at a centre of excellence for endometriosis. Also, the surgeon was completely blinded to the mapping proforma but not to the radiology report which could not be completely avoided for proper surgical management.

\section{Conclusion}

TVS allows a systematic comprehensive and accurate assessment of the size and location of pelvic and deep infiltrating endometriosis. The use of E-PEP can be utilized by the radiologist and surgeon to ensure that mapping information is correctly passed on. Precise mapping of endometriosis is pivotal for patient counselling to tailor the most appropriate surgical approach enhancing the patient quality of life and fertility, ensuring 
radical excision of the disease and minimizing operative and post-operative complications.

\section{Abbreviations}

BSGE: British Society for Gynaecological Endoscopy; DIE: Deep infiltrating endometriosis; E-PEP: Endometriosis Preoperative Evaluation Proforma; IDEA: International Deep Endometriosis Analysis; IVF: In vitro fertilization; MRI: Magnetic resonance imaging; RVS: Rectovaginal septum; SD: Standard deviation; SPSS: Statistical Package for the Social Science; STARD: Statement for Reporting Diagnostic Accuracy Studies; TP: True positive; TRS: Transrectal sonography; TUI: Tomographic ultrasound imaging; TVS: Transvaginal sonography; USL: Uterosacral ligament; VAS: Visual analogue scale; VCl: Volume contrast imaging

\section{Acknowledgements}

The authors would like to acknowledge Dr. Szabolcs Papp for his expertise as a colorectal surgeon and Dr. Magdy Ibrahim for providing the statistical advice for this manuscript.

\section{Authors' contributions}

The scientific guarantor of this study is C.N. S.M.E.: Review of literature, suggesting the idea, data collection and analysis, performing ultrasound and reporting ultrasound findings, writing the original draft, reviewing and editing the manuscript. N.A.: Data collection and analysis, performing ultrasound and reporting ultrasound findings, reviewing and editing the manuscript. C.N.: Data collection and analysis, perform the surgery and reporting surgical findings, reviewing and editing the manuscript. All authors have read and approved the manuscript.

\section{Funding}

The authors declare that they did not receive funding for this research.

\section{Availability of data and materials}

The data sets used and analysed during the current study are available from the corresponding author on reasonable request.

\section{Declarations}

\section{Ethics approval and consent to participate}

Medcare Hospitals \& Clinics Ethics Committee approval was obtained. Reference number is not applicable. Written informed consent was obtained from all patients who agreed to take part in this study.

\section{Consent for publication}

All patients included in this research gave written informed consent to publish the data contained within the study.

\section{Competing interests}

The authors declare that they have no competing interests.

\section{Author details}

'Department of Radiology, National Cancer Institute, Cairo University, Cairo, Egypt. ${ }^{2}$ Department of Radiology, Medcare Women and Children Hospital, Sheikh Zayed Road, P.O Box 215565, Dubai, UAE. ${ }^{3}$ Department of Obstetrics and Gynaecology, Medcare Women and Children Hospital, Sheikh Zayed Road, P. O Box 215565, Dubai, UAE.

\section{Received: 16 April 2021 Accepted: 3 June 2021}

\section{Published online: 28 June 2021}

\section{References}

1. Bulun SE (2009) Endometriosis. N Engl J Med 360(3):268-279. https://doi. org/10.1056/NEJMra0804690

2. Chapron C, Fauconnier A, Vieira M, Barakat H, Dousset B, Pansini V, VacherLavenu MC, Dubuisson JB (2003) Anatomical distribution of deeply infiltrating endometriosis: surgical implications and proposition for a classification. Hum Reprod 18(1):157-161. https://doi.org/10.1093/humrep/deg009

3. Benacerraf BR, Groszmann Y, Hornstein MD, Bromley B (2015) Deep infiltrating endometriosis of the bowel wall: the comet sign. J Ultrasound Med. 34(3):537-542. https://doi.org/10.7863/ultra.34.3.537
4. Koninckx PR, Ussia A, Adamyan L, Wattiez A, Donnez J (2012) Deep endometriosis: definition, diagnosis, and treatment. Fertil Steril. 98(3):564571. https://doi.org/10.1016/j.fertnstert.2012.07.1061

5. Vercellini P, Trespidi L, De Giorgi O, Cortesi I, Parazzini F, Crosignani PG (1996) Endometriosis and pelvic pain: relation to disease stage and localization. Fertil Steril 65(2):299-304. https://doi.org/10.1016/50015-0282(16)58089-3

6. Nnoaham KE, Hummelshoj L, Webster P, d'Hooghe T, de Cicco Nardone F, de Cicco Nardone C, Jenkinson C, Kennedy SH, Zondervan KT, World Endometriosis Research Foundation Global Study of Women's Health consortium (2011) Impact of endometriosis on quality of life and work productivity: a multicenter study across ten countries. Fertil Steril 96(2):366373. https://doi.org/10.1016/j.fertnstert.2011.05.090

7. Koninckx PR, Martin D (1994) Treatment of deeply infiltrating endometriosis. Curr Opin Obstet Gynecol 6(3):231-241. https://doi.org/10.1097/00001703-1 99406000-00006

8. Chapron C, Dubuisson JB, Pansini V, Vieira M, Fauconnier A, Barakat H, Dousset $B$ (2002) Routine clinical examination is not sufficient for diagnosing and locating deeply infiltrating endometriosis. J Am Assoc Gynecol Laparosc 9(2): 115-119. https://doi.org/10.1016/S1074-3804(05)60117-X

9. Exacoustos C, Malzoni M, Di Giovanni A et al (2014) Ultrasound mapping system for the surgical management of deep infiltrating endometriosis. Fertil Steril 102(1):143-150. https://doi.org/10.1016/j.fertnstert.2014.03.043

10. Dunselman GA, Vermeulen N, Becker C et al (2014) ESHRE guideline: management of women with endometriosis. Hum Reprod29:400-412

11. Exacoustos C, Manganaro L, Zupi E (2014) Imaging for the evaluation of endometriosis and adenomyosis. Best Pract Res Clin Obstet Gynaecol 28(5): 655-681. https://doi.org/10.1016/j.bpobgyn.2014.04.010

12. Fedele L, Bianchi S, Portuese A, Borruto F, Dorta M (1998) Transrectal ultrasonography in the assessment of rectovaginal endometriosis. Obstet Gynecol 91(3):444-448. https://doi.org/10.1016/S0029-7844(97)00688-1

13. Bazot M, Daraï E (2005) Sonography and MR imaging for the assessment of deep pelvic endometriosis. J Minim Invasive Gynecol 12(2):178-185. https:// doi.org/10.1016/j.jmig.2005.01.014

14. Vimercati A, Achilarre MT, Scardapane A, Lorusso F, Ceci O, Mangiatordi G, Angelelli G, van Herendael B, Selvaggi L, Bettocchi S (2012) Accuracy of transvaginal sonography and contrast-enhanced magnetic resonancecolonography for the presurgical staging of deep infiltrating endometriosis. Ultrasound Obstet Gynecol 40(5):592-603. https://doi.org/10.1002/uog.11179

15. Guerriero S, Alcázar JL, Pascual MA, Ajossa S, Perniciano M, Piras A, Mais V, Piras B, Schirru F, Benedetto MG, Saba L (2018) Deep infiltrating endometriosis: comparison between 2-dimensional ultrasonography (US), 3dimensional US, and magnetic resonance imaging. J Ultrasound Med 37(6): 1511-1521. https://doi.org/10.1002/jum.14496

16. Alborzi S, Rasekhi A, Shomali Z, Madadi G, Alborzi M, Kazemi M, Hosseini Nohandani A (2018) Diagnostic accuracy of magnetic resonance imaging, transvaginal, and transrectal ultrasonography in deep infiltrating endometriosis. Medicine (Baltimore) 97(8):e9536. https://doi.org/https://doi. org/10.1097/MD.0000000000009536.

17. Fraser MA, Agarwal S, Chen I, Singh SS (2015) Routine vs. expert-guided transvaginal ultrasound in the diagnosis of endometriosis: a retrospective review. Abdom Imaging 40(3):587-594. https://doi.org/10.1007/s00261-014-0243-5

18. Bossuyt PM, Cohen JF, Gatsonis CA, Korevaar DA, STARD group (2016) STAR D 2015: updated reporting guidelines for all diagnostic accuracy studies. Ann Transl Med 4:85

19. Langley GB, Sheppeard $H$ (1985) The visual analogue scale: its use in pain measurement. Rheumatol Int 5(4):145-148. https://doi.org/10.1007/BF00541514

20. Revill SI, Robinson JO, Rosen M, Hogg MI (1976) The reliability of a linear analogue for evaluating pain. Anaesthesia 31(9):1191-1198. https://doi.org/1 0.1111/j.1365-2044.1976.tb11971.x

21. Guerriero $S$, Condous $G$, van den Bosch T, Valentin L, Leone FPG, van Schoubroeck D, Exacoustos C, Installé AJF, Martins WP, Abrao MS, Hudelist G, Bazot M, Alcazar JL, Gonçalves MO, Pascual MA, Ajossa S, Savelli L, Dunham R, Reid S, Menakaya U, Bourne T, Ferrero S, Leon M, Bignardi T, Holland T, Jurkovic D, Benacerraf B, Osuga Y, Somigliana E, Timmerman D (2016) Systematic approach to sonographic evaluation of the pelvis in women with suspected endometriosis, including terms, definitions and measurements: a consensus opinion from the international deep endometriosis analysis (IDEA) group. Ultrasound Obstet Gynecol 48(3):318332. https://doi.org/10.1002/uog.15955

22. Reid S, Lu C, Casikar I, Reid G, Abbott J, Cario G, Chou D, Kowalski D, Cooper M, Condous G (2013) Prediction of pouch of douglas obliteration in women 
with suspected endometriosis using a new real-time dynamic transvaginal ultrasound technique: the sliding sign. Ultrasound Obstet Gynecol 41(6): 685-691. https://doi.org/10.1002/uog.12305

23. Cunningham RK, Horrow MM, Smith RJ, Springer J (2018) Adenomyosis: a sonographic diagnosis. Radiographics 38(5):1576-1589. https://doi.org/1 $0.1148 /$ rg. 2018180080

24. Van Holsbeke C, Van Calster B, Guerriero S et al (2010) Endometriomas: their ultrasound characteristics. Ultrasound Obstet Gynecol 35(6):730-740. https:// doi.org/10.1002/uog.7668

25. Ghezzi F, Raio L, Cromi A et al (2005) "Kissing ovaries": a sonographic sign of moderate to severe endometriosis. Fertil Steril 83(1):143-147. https://doi. org/10.1016/j.fertnstert.2004.05.094

26. Okaro E, Condous G, Khalid A et al (2006) The use of ultrasound-based 'Soft markers' for the prediction of pelvic pathology in women with chronic pelvic pain-can we reduce the need for laparoscopy? BJOB 113:251-256

27. Tuttlies F, Keckstein J, Ulrich U, Possover M, Schweppe K, Wustlich M, Buchweitz O, Greb R, Kandolf O, Mangold R, Masetti W, Neis K, Rauter G, Reeka N, Richter O, Schindler A, Sillem M, Terruhn V, Tinneberg H (2005) ENZIAN-score, a classification of deep infiltrating endometriosis. Zentralbl Gynakol 127(05):275-281. https://doi.org/10.1055/s-2005-836904

28. Bazot M, Malzy P, Cortez A, Roseau G, Amouyal P, Daraï E (2007) Accuracy of transvaginal sonography and rectal endoscopic sonography in the diagnosis of deep infiltrating endometriosis. Ultrasound Obstet Gynecol 30(7):994-1001. https://doi.org/10.1002/uog.4070

29. Koga K, Osuga Y, Yano T, Momoeda M, Yoshino O, Hirota Y, Kugu K, Nishii O, Tsutsumi O, Taketani Y (2003) Characteristic images of deeply infiltrating rectosigmoid endometriosis on transvaginal and transrectal ultrasonography. Hum Reprod 18(6):1328-1333. https://doi.org/10.1093/humrep/deg243

30. Byrne D, Curnow T, Smith P, Cutner A, Saridogan E, Clark TJ (2018) Laparoscopic excision of deep rectovaginal endometriosis in BSGE endometriosis centres: a multicentre prospective cohort study. BMJ Open 8(4):e018924.https://doi.org/https://doi.org/10.1136/bmjopen-2017-018924.

31. Fratelli N, Scioscia M, Bassi E, Musola M, Minelli L, Trivella G (2013) Transvaginal sonography for preoperative assessment of deep endometriosis. J Clin Ultrasound 41(2):69-75. https:/doi.org/10.1002/jcu.22018

32. Hernández Gutiérrez A, Spagnolo E, Hidalgo P, López A, Zapardiel I, Rodriguez R (2019) Magnetic resonance imaging versus transvaginal ultrasound for complete survey of the pelvic compartments among patients with deep infiltrating endometriosis. Int J Gynecol Obstet 146(3):380-385. https://doi.org/10.1002/ijgo.12894

33. Tammaa A, Fritzer N, Lozano P, Krell A, Salzer H, Salama M, Hudelist G (2015) Interobserver agreement and accuracy of non-invasive diagnosis of endometriosis by transvaginal sonography. Ultrasound Obstet Gynecol 46(6):737-740. https://doi.org/10.1002/uog.14843

34. Guerriero S, Ajossa S, Gerada M, Virgilio B, Angioni S, Melis GB (2008) Diagnostic value of transvaginal 'tenderness-guided' ultrasonography for the prediction of location of deep endometriosis. Hum Reprod 23(11):24522457. https://doi.org/10.1093/humrep/den293

35. Grasso RF, Di Giacomo V, Sedati P et al (2009) Diagnosis of deep infiltrating endometriosis: accuracy of magnetic resonance imaging and transvaginal 3D ultrasonography. Abdom Imaging 35:716-725

36. Holland TK, Cutner A, Saridogan E, Mavrelos D, Pateman K, Jurkovic D (2013) Ultrasound mapping of pelvic endometriosis: does the location and number of lesions affect the diagnostic accuracy? a multicentre diagnostic accuracy study. BMC Women's Health 13 1:43. https://doi.org/https://doi. org/10.1186/1472-6874-13-43

37. Pattanasri M, Ades A, Nanayakkara P (2020) Correlation between ultrasound findings and laparoscopy in prediction of deep infiltrating endometriosis (DIE). Aust N Z J Obstet Gynaecol 60(6):946-951. https://doi.org/10.1111/ajo.13242

38. Guerriero S, Ajossa S, Orozco R, Perniciano M, Jurado M, Melis GB, Alcazar JL (2016) Accuracy of transvaginal ultrasound for diagnosis of deep endometriosis in the rectosigmoid: systematic review and meta-analysis. Ultrasound Obstet Gynecol 47(3):281-289. https://doi.org/10.1002/uog.15662

39. Hudelist G, Tuttlies F, Rauter G, Pucher S, Keckstein J (2009) Can transvaginal sonography predict infiltration depth in patients with deep infiltrating endometriosis of the rectum? Hum Reprod 24(5):1012-1017. https://doi. org/10.1093/humrep/dep014

40. Donnez O, Roman H (2017) Choosing the right surgical technique for deep endometriosis: shaving, disc excision, or bowel resection? Fertil Steril 108(6): 931-942. https://doi.org/10.1016/j.fertnstert.2017.09.006
41. Roman H, Bubenheim M, Huet E, Bridoux V, Zacharopoulou C, Daraï E, Collinet $P$, Tuech JJ (2018) Conservative surgery versus colorectal resection in deep endometriosis infiltrating the rectum: a randomized trial. Hum Reprod 33(1):47-57. https://doi.org/10.1093/humrep/dex336

42. Leone Roberti Maggiore U, Ferrero S, Candiani M, Somigliana E, Viganò P, Vercellini P (2017) Bladder endometriosis: a systematic review of pathogenesis, diagnosis, treatment, impact on fertility, and risk of malignant transformation. Eur Urol 71(5):790-807. https://doi.org/10.1016/j.eururo.2016.12.015

\section{Publisher's Note}

Springer Nature remains neutral with regard to jurisdictional claims in published maps and institutional affiliations.

\section{Submit your manuscript to a SpringerOpen ${ }^{\circ}$ journal and benefit from:}

- Convenient online submission

- Rigorous peer review

- Open access: articles freely available online

High visibility within the field

- Retaining the copyright to your article

Submit your next manuscript at $\boldsymbol{\nabla}$ springeropen.com 